\title{
Identification of differentially expressed host genes in Bombyx mori nucleopolyhedrovirus infected cells by using subtractive hybridization
}

\author{
Masashi Iwanaga, ${ }^{1,2, *, \dagger}$ Toru ShImada, ${ }^{2}$ Masahiko Kobayashi ${ }^{2}$ and WonKyung Kang ${ }^{1}$ \\ ${ }^{1}$ Molecular Entomology Laboratory, RIKEN; Wako 351-0198, Japan \\ ${ }^{2}$ Department of Agricultural and Environmental Biology, Graduate School of Agricultural and Life Sciences, The University of \\ Tokyo; Bunkyo-ku, Tokyo 113-8657, Japan
}

(Received 10 April 2006; Accepted 9 November 2006)

\begin{abstract}
Following baculovirus infection, the level of host messenger RNA (mRNA) declines and the synthesis of host proteins is shutoff in virus-infected cells. To comprehensively understand the regulation of host gene expression by Bombyx mori nucleopolyhedrovirus (BmNPV), we took a complementary DNA (cDNA) subtraction approach. Northern blot analysis was then performed to confirm whether obtained clones are differentially expressed. From these analyses, we obtained 4 down-, 7 up- and 2 non-regulated host gene candidates during the early stage of infection. Sequence analyses showed that these may encode proteins involved in transcription, cell cycle, cell adhesion, protein degradation, apoptosis or energy metabolism. We then measured the ADP/ATP ratio to address the response of host energy metabolism upon baculovirus infection. The ADP/ATP ratio showed cell death-like rapid increase following BmNPV infection with a transient decrease during $12-24 \mathrm{~h}$ post-infection (p.i.). Taken together, our results suggest that general events in host cells are controlled at the level of mRNA expression by BmNPV infection.
\end{abstract}

Key words: Baculovirus; cDNA subtraction; differential gene expression; energy metabolism; baculovirus host regulation

\section{INTRODUCTION}

Baculoviridae are a diverse family of pathogens that are infectious for arthropods, particularly Lepidoptera insects. Nucleopolyhedroviruses (NPVs), a genus of Baculoviridae, have large circular, supercoiled, and double-stranded DNA genomes within a rod-shaped virion. NPVs such as Autographa californica NPV (AcNPV) and Bombyx mori NPV (BmNPV) are commonly used as expression vectors for foreign genes in cultured cells and larvae (O'Reilly et al., 1992; Choudary et al., 1995).

To accomplish virus replication in the host insect cells, NPV requires interaction with the host. For example, following virion entry, AcNPV induces the formation of actin cables as a result of the activity of a virus protein known as actin rearrangement factor (Roncarati and Knebel-Morsdorf, 1997). These actin cables may assist the transport of virus nucleocapsid to the nucleus
(Lanier and Volkman, 1998). Additionally, AcNPV infection results in arrest of the host cell cycle at the $\mathrm{G} 2 / \mathrm{M}$ transition phase by the function of a virus protein IE2 (Braunagel et al., 1998; Prikhod'ko and Miller, 1998). AcNPV also encodes ODV-EC27 protein that could be associated with both $\mathrm{CDC} 2$ and $\mathrm{Cdk} 6$ proteins, and this association in active kinase complexes might result in regulating host cell cycle by phosphorylation of histone $\mathrm{H} 1$ and retinoblastoma protein (Belyavskyi et al., 1998). Furthermore, NPVs encode anti-apoptotic genes such as p35 or inhibitor of apoptosis (iap) to prevent premature cell death (Clem and Miller, 1993; Kamita et al., 1993; Birnbaum et al., 1994). Previously, Iwanaga et al. (2000) reported that BmNPV infection blocks the progression of fat body degradation during metamorphosis in silkworms. They also reported that virus infection restores host protein synthesis that was to be repressed at a low level during pupal-adult development. Degradation of fat body also has been shown

\footnotetext{
* To whom correspondence should be addressed at: E-mail: iwanaga@cc.utsunomiya-u.ac.jp

${ }^{\dagger}$ Present address: Department of Bioproductive Science, Utsunomiya University, Minemachi 350, Utsunomiya, Tochigi 321-8505, Japan DOI: $10.1303 /$ aez.2007.151
} 
to be prevented by infection with either $p 35$ or iap 1 deletion mutant, suggesting that a mechanism other than inhibition of apoptosis may be involved in this prevention (Iwanaga et al., 2000).

Genome-wide differential gene expressions have been examined at the RNA level. Several mRNAs have been cloned in cirrhotic tissue, oncogenetransformed cells or virus-infected cells ( $\mathrm{Su}$ et al., 1997; Shackel et al., 2003). In baculovirus, comparative expressed-sequence-tag (EST) was analyzed in BmN cells infected with BmNPV (Okano et al., 2001), and differential display approaches were examined both in vitro and in vivo (Nobiron et al., 2003; Xu et al., 2005). Nobiron et al. (2003) reported that the mRNA level of host heat shock protein cognate 70 ( $h s c 70$ ) gene was up-regulated in Spodoptera frugiperda cells (Sf9) infected with AcNPV. Xu et al. (2005) also reported that the mRNA level of host suppressor of profilin 2 (sop2) gene was up-regulated at the silkworm midgut infected with BmNPV. In addition, it has been reported that some genes relating to mitochondria such as cytochrome oxidase I and III, ADP/ATP translocase do not follow the host mRNA shutoff pattern (Ooi and Miller, 1988; Okano et al., 2001). Therefore, it is interesting to identify the presence and type of host genes that are up regulated by baculovirus infection although the steady-state levels of cellular mRNAs and protein synthesis of most host genes decline by baculovirus infection (Carstens et al., 1979; Sugimori et al., 1991).

In this report, we adopted a global approach to look for differentially expressed host genes in the early phase of BmNPV infection by using cDNA subtractive hybridization. Differentially expressed patterns of obtained genes were then examined by Northern blot analyses. Sequence analyses of these clones showed high similarity to the genes involved in transcription, cell cycle, cell adhesion, protein degradation, apoptosis and energy metabolism. In addition, we measured the ADP/ATP ratio to investigate the response of energy metabolism to virus infection since our study suggests that genes involved in energy metabolism and ATP-dependent proteasome are up-regulated. The ratios showed cell death-like rapid increase following virus infection with a transient decrease during $12-24 \mathrm{~h}$ p.i.

\section{MATERIALS AND METHODS}

Cell line and virus. The $\mathrm{BmN}-4(\mathrm{BmN})$ cell line was maintained in TC-100 with $10 \%$ fetal bovine serum as described previously (Maeda, 1989). The BmNPV T3 isolate (Maeda et al., 1985) was propagated on $\mathrm{BmN}$ cells as described (Maeda, 1995).

Infection time course. BmN cells were infected with BmNPV at an MOI of 10 or medium only for mock infection. After $1 \mathrm{~h}$ adsorption, medium was replaced with fresh medium, and then cells were harvested at $2 \mathrm{~h}$ and $6 \mathrm{~h}$ p.i. at appropriate times.

Quantitation of RNA amounts. Total RNAs and mRNAs were directly extracted from $\mathrm{BmN}$ cells $\left(4 \times 10^{6}\right)$ infected with BmNPV $(\mathrm{MOI}=10)$ in the designated time course using an RNeasy total RNA extraction kit (Qiagen) and Micro-FastTrack 2.0 (Invitrogen), respectively. Quantitation of RNA amounts was performed using UV absorbance (Beckman, DU-7400). Each assay was performed three times to verify the results.

Subtractive hybridization, suppression PCR and Northern blotting. Total RNAs were isolated from mock- or BmNPV-infected cells using a Total RNA Isolation Kit (5Prime-3Prime). Poly(A)+ RNA was purified from $800 \mu \mathrm{g}$ of total RNA by using FastTrack 2.0 (Invitrogen). Subtractive hybridization was performed using the PCR-Select cDNA subtraction kit (Clontech) by following the manufacturer's instruction. Briefly, the cDNA pool to be screened for differentially expressed genes was named as the tester pool, which was compared with a reference driver pool. First, these cDNA pools were digested with $R s a \mathrm{I}$, and then two tester cDNAs were ligated to each adaptor, 1 and $2 \mathrm{R}$. Next, the tester cDNA was hybridized to excess driver cDNA, and subsequently re-hybridized to each other. The differentially expressed cDNA with adaptor 1 and $2 \mathrm{R}$ in the tester pool was amplified by polymerase chain reaction (PCR) with adaptorspecific primers. Amplified DNA was applied to size-sep column 400 (Amersham) for the exclusion of short-length DNA, and then cloned into the pGEM-T vector (Promega). The nucleotide sequences of cloned DNA were determined using an ABI 377 DNA sequencer (Applied Biosystems), and then the nucleotide sequences were used to search for SilkBase (http://papilio.ab.a.utokyo.ac.jp/silkbase/; Bombyx Genome Database 
Working Group; Mita et al., 2003), KAIKOBLAST (http://kaikoblast.dna.affrc.go.jp/; Silkworm Genome Research Program) and BLAST (GenBank). Finally, Northern analyses were performed as described previously (Iwanaga et al., 2002). Probes were amplified by PCR using M13 forward and reverse primers, and the subclones described above and then uniformly labeled with $\left[\alpha{ }^{32} \mathrm{P}\right]-$ dCTP using the Ready-To-Go DNA labeling kit (Amersham).

Relative ADP/ATP ratio in BmNPV-infected cells. The ADP/ATP ratio was measured using an ApoSENSOR ADP/ATP Ratio Assay Kit as per the manufacturer's protocol (BioVision). Mock- or BmNPV-infected $\mathrm{BmN}$ cells $\left(1 \times 10^{4}\right)$ were suspended in nuclear releasing reagent to subsequently measure ATP and ADP levels. The assay utilized the enzyme luciferase to catalyze the formation of light from ATP and luciferin. Light was detected by a multilabeled counter (Perkin-Elmer, Wallac ARVO sx1420). Each assay was performed three times to verify the results.

\section{RESULTS AND DISCUSSION}

\section{Relative amounts of mRNA in BmN cells in- fected with BmNPV}

In Baculovirus infection, viral genes are transcribed in a settled manner with a decline in host mRNA synthesis (Ooi and Miller, 1988; Iwanaga et al., 2004); however, it is not likely that the expression of entire host genes is down-regulated. It has been reported that several host gene expressions are indeed up-regulated following virus infection (Nobiron et al., 2003; Xu et al., 2005). Therefore, we quantified the level of both total RNA and mRNA at each infection time against that of mockinfected cells to see whether there is any change in the relative amount of RNAs during BmNPV infection. A relative amount of total RNAs showed no significant change following BmNPV infection, while a relative amount of mRNAs showed a statistically significant difference (ANOVA, $p<0.0001$ ) (Fig. 1). The mRNA levels in the very late phase (24-72 h p.i.) were 3 -fold higher than in the early phase (2-6h p.i.). The level of mRNA slightly increased between $2 \mathrm{~h}$ p.i. and $6 \mathrm{~h}$ p.i., although little decrease was observed at $12 \mathrm{~h}$ p.i., the beginning of the late phase. This subtle increase at $2 \mathrm{~h}$ p.i. showed a significant difference from mock infec-

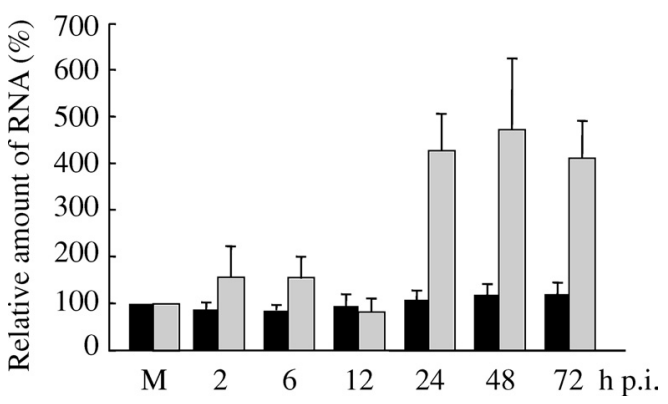

Fig. 1. Relative amount of both total RNA and mRNA in virus-infected $\mathrm{BmN}$ cells. $\mathrm{BmN}$ cells $\left(4 \times 10^{6}\right)$ were infected with BmNPV at an MOI of 10, harvested at designated times and subjected to RNA extraction. Dark and light bars indicate the relative amount of total RNA and mRNA to mock infection, respectively. The results are the average of three independent experiments and standard errors. $\mathrm{M}$, mock infected.

tion (Tukey test, $p<0.05$ ), suggesting that some genes might be differentially regulated by virus infection during this phase; however, the transient decrease at $12 \mathrm{~h}$ p.i. did not differ significantly from mock infection. Therefore, we selected mock, 2 and $6 \mathrm{~h}$ p.i. to identify differentially expressed genes by using cDNA subtraction.

\section{cDNA subtractions}

In this study, six combinations of subtractive hybridization were performed to look for genes that were differentially expressed (Table 1). In group A, $2 \mathrm{~h}$ p.i. and $6 \mathrm{~h}$ p.i. cDNAs were subtracted from mock cDNA (M/2 and $M / 6$, respectively) and $6 \mathrm{~h}$ p.i. cDNA was subtracted from $2 \mathrm{~h}$ p.i. cDNA $(2 / 6)$ to screen for down-regulated genes. In group $\mathrm{B}$, mock cDNA was subtracted from $2 \mathrm{~h}$ p.i. and $6 \mathrm{~h}$ p.i. cDNAs (2/M and $6 / \mathrm{M}$, respectively) and $2 \mathrm{~h}$ p.i. cDNA was subtracted from $6 \mathrm{~h}$ p.i. cDNA $(6 / 2)$ to screen for up-regulated genes. After suppression PCR, 526 clones were then characterized by nucleotide sequencing and a database search for homologous sequences using SilkBase, KAIKOBLAST and BLAST search. After the removal of multiple clones, we identified 150 independent clones (32 NPV, 2 macula-like latent virus and 116 host genes). The major host or latent virus genes that appeared more than twice in any subtraction library were profiled in Table 2 . Nineteen host genes showed high similarity to the genes relating to gene/protein expression, cell structure/mobility, cell/organism defense and metabolism. On the other hand, two genes were en- 
Table 1. The summary of subtraction analysis

\begin{tabular}{|c|c|c|c|c|c|c|}
\hline & Tester & Driver & $\begin{array}{c}\text { Subtracted } \\
\text { cDNA library }\end{array}$ & $\begin{array}{c}\text { Clones } \\
\text { sequenced }\end{array}$ & $\begin{array}{l}\text { Virus clones } \\
\text { (ratio, \%) }\end{array}$ & $\begin{array}{c}\text { Differentially } \\
\text { expressed host gene }\end{array}$ \\
\hline \multirow{3}{*}{ Group A } & mock & 2 h p.i. & $\mathrm{M} / 2$ & 102 & $2(2.0)$ & 3 \\
\hline & mock & $6 \mathrm{~h}$ p.i. & $\mathrm{M} / 6$ & 111 & $1(0.9)$ & 1 \\
\hline & 2 h p.i. & $6 \mathrm{~h} \mathrm{p.i.}$ & $2 / 6$ & 121 & $0(0)$ & 5 \\
\hline \multirow{3}{*}{ Group B } & $2 \mathrm{~h}$ p.i. & mock & $2 / \mathrm{M}$ & 59 & $41(69.5)$ & 0 \\
\hline & $6 \mathrm{~h}$ p.i. & mock & $6 / \mathrm{M}$ & 30 & $14(46.7)$ & 0 \\
\hline & $6 \mathrm{~h}$ p.i. & 2 h p.i. & $6 / 2$ & 103 & $46(44.7)$ & 4 \\
\hline
\end{tabular}

Table 2. Expression profiles of host and MLV genes from cDNA subtraction library

\begin{tabular}{|c|c|c|c|c|c|c|c|}
\hline \multirow{2}{*}{ Putative definition } & \multirow{2}{*}{ Accession no. ${ }^{\mathrm{a}}$} & \multicolumn{6}{|c|}{ Library } \\
\hline & & $\mathrm{M} / 2$ & $\mathrm{M} / 6$ & $2 / 6$ & $2 / \mathrm{M}$ & $6 / \mathrm{M}$ & $6 / 2$ \\
\hline \multicolumn{8}{|l|}{ Gene/protein expression } \\
\hline $26 \mathrm{~S}$ proteasome & $\mathrm{AB} 003102^{\mathrm{b}}$ & 1 & - & 1 & - & - & - \\
\hline 40S ribosomal protein S5 & P46782 & - & - & 2 & - & - & - \\
\hline 60S ribosomal protein L15 & P30736 & - & - & 1 & - & - & 1 \\
\hline $60 \mathrm{~S}$ ribosomal protein L3 & O16797 & - & - & - & - & - & 2 \\
\hline 60 S ribosomal protein L37 & P02403 & - & - & 3 & - & 1 & - \\
\hline $60 \mathrm{~S}$ ribosomal protein $\mathrm{L} 7 \mathrm{~A}$ & P12970 & - & - & 1 & - & - & 2 \\
\hline Elongation Factor-2 & P13060 & 1 & 2 & 1 & - & - & - \\
\hline TAFII-SUBUNIT 5 & P49846 & - & - & 1 & - & 1 & - \\
\hline \multicolumn{8}{|l|}{ Cell structure/mobility } \\
\hline Actin, cytoplasmic A3 & P04829 & - & 1 & - & 1 & - & 1 \\
\hline Tubulin alpha-1 & P06603 & - & - & 1 & - & 1 & - \\
\hline \multicolumn{8}{|l|}{ Cell defense/organism defense } \\
\hline Jun and 14-3-3 zeta & Y $12573^{b}$ & - & 1 & 2 & - & - & - \\
\hline HSC70 & $\mathrm{U} 23504^{\mathrm{b}}$ & - & 1 & 2 & - & - & - \\
\hline \multicolumn{8}{|l|}{ Metabolism } \\
\hline Cytochrome c oxidase poly 1 & $\mathrm{AF} 044013^{\mathrm{b}}$ & 1 & - & 1 & 2 & - & - \\
\hline Cytochrome c oxidase poly 3 & P00417 & - & - & 1 & - & - & - \\
\hline Pyruvate dehydrogenase E1 & P26268 & - & - & 2 & - & 1 & - \\
\hline Vacuolar ATPase C & $\mathrm{U} 03374^{\mathrm{b}}$ & - & - & - & - & - & 2 \\
\hline Xanthine dehydrogenase & $\mathrm{AB} 005911^{\mathrm{b}}$ & - & - & 2 & - & - & - \\
\hline \multicolumn{8}{|l|}{ Unclassified } \\
\hline Ferritin lower subunit & P07797 & - & - & 2 & - & - & - \\
\hline Selenoprotein P-like protein & P49907 & - & 2 & - & - & - & - \\
\hline \multicolumn{8}{|l|}{ MLV sequence } \\
\hline RNA replicase polyprotein & $\mathrm{AB} 186123^{\mathrm{b}}$ & - & 2 & - & - & - & - \\
\hline Coat protein & $\mathrm{AB} 186123^{\mathrm{b}}$ & 9 & 14 & 5 & - & 2 & 2 \\
\hline
\end{tabular}

Among the six cDNA subtraction library, the host and MLV genes that appeared at least twice in any library were examined.

${ }^{a}$ Accession numbers of PIR and SWISS-PROT.

${ }^{\mathrm{b}}$ Accession numbers of GenBank/EMBL/DDBJ.

- , not detected in the sequenced cDNAs in each library.

coded in the macula-like latent virus (MLV) genome. Coat protein gene was frequently observed (appeared 32 times). A subset of clones, especially from group $\mathrm{B}$, showed high similarity to BmNPV genes such as $i e 1$, egt, $p 35$, gp64 and $p 39$
(Table 3). It was observed that the most abundant virus gene was the bro gene (appeared 13 times). The relative content of viral transcripts in group A was 2.0, 0.9 and $0 \%$ in $\mathrm{M} / 2, \mathrm{M} / 6$ and 2/6 libraries, respectively (Table 1). On the other hand, it was 
Table 3. Expression profiles of NPV genes from cDNA subtraction library

\begin{tabular}{|c|c|c|c|c|c|c|c|}
\hline \multirow{2}{*}{ ORF } & \multirow{2}{*}{ Gene } & \multicolumn{6}{|c|}{ Library } \\
\hline & & $\mathrm{M} / 2$ & $\mathrm{M} / 6$ & $2 / 6$ & $2 / \mathrm{M}$ & $6 / \mathrm{M}$ & $6 / 2$ \\
\hline 4 & & - & - & - & 3 & - & 1 \\
\hline 7 & egt & - & - & - & 4 & 3 & 3 \\
\hline 13 & & - & - & - & - & 2 & - \\
\hline 16 & $d b p$ & - & - & - & 3 & - & 2 \\
\hline 27 & p39 & - & - & - & 2 & 1 & 3 \\
\hline 29 & & - & - & - & - & - & 2 \\
\hline 67 & & - & - & - & - & - & 2 \\
\hline 68 & & 1 & - & - & 1 & 1 & 4 \\
\hline 74 & lef4 & - & - & - & - & - & 2 \\
\hline 78 & dna helicase & - & - & - & - & 1 & 9 \\
\hline 81 & bro & 1 & - & - & 3 & 1 & 8 \\
\hline 100 & & - & - & - & - & 2 & - \\
\hline 105 & gp64 & - & - & - & 6 & - & - \\
\hline 112 & p35 & - & - & - & 6 & - & - \\
\hline 116 & me53 & - & - & - & 1 & - & - \\
\hline 123 & iel & - & 1 & - & 3 & - & - \\
\hline 127 & $i e 2$ & - & - & - & 3 & - & - \\
\hline
\end{tabular}

Among the six cDNA subtraction library, the NPV genes that appeared at least twice in any library were examined. -, not detected in the sequenced cDNAs in each library.

$69.5,46.7$ and $44.7 \%$ in $2 / \mathrm{M}, 6 / \mathrm{M}$ and $6 / 2$ libraries of group B, respectively. This suggests that our subtraction analysis was efficient enough to identify differentially expressed host genes.

\section{Differentially expressed host genes}

Northern blotting was then performed to confirm whether the clones identified as host-encoded genes by subtractive hybridization were differentially expressed. Unfortunately, we were not able to confirm the expression of most clones because of undetectable or unclear signals (data not shown); however, we were able to confirm the expression of 13 clones (4 down-, 7 up- and 2 non-regulated genes) (Table 4 and Fig. 2). Furthermore, some clones showed a diverse expressed pattern between cDNA subtraction screening and Northern analysis. The efficiency of cDNA subtraction might be affected by a slight difference of host gene expression between the infection stages or we might fail to subtract thoroughly because of excessive amounts of both NPV and MLV cDNAs.

\section{Down-regulated genes}

By Northern blot analysis, 4 clones were con- firmed as down-regulated genes in the early phase (Fig. 2 and Table 4A). The nucleotide sequences of 6/2-1, 6/2-2 and 2/6-1 transcripts showed highly similarity to RNA polymerase II, D. melanogaster LD46360 and ferritin lower subunit homologues, respectively. On the other hand, the 2/6-2 clone showed no similarity to known protein but was identified as the NRPG0148 clone from SilkBase. Northern hybridization showed that the expression of RNA polymerase II homologue (6/2-1) was down-regulated at $6 \mathrm{~h}$ p.i. (Fig. 2A). NPV genes are transcribed by host-encoded RNA polymerase II only during the early phase of infection and virusencoded RNA polymerase is used in the late phase (Grula et al., 1981; Hoopes and Rohrmann, 1991). Therefore, our result suggested that down regulation of host RNA polymerase II may lead to this turning point. In addition, the transcript of $6 / 2-2$ showed a subtle decrease at $2 \mathrm{~h}$ p.i. (Fig. 2A). This clone showed a similarity to the $D$. melanogaster LD46360 homologue. Interestingly, LD46360 was a homologue of acinus (61\% amino acid identity for human acinus $\left.S^{\prime}, \mathrm{AF} 124728\right)$ that promotes nuclear DNA condensation by Caspase-3 processing in the apoptotic cascade (Sahara et al., 1999). Therefore, this would provide important information that lepidopteran acinus also functions on chromatin condensation in insect cells undergoing apoptosis.

\section{Up-regulated genes}

Seven clones were confirmed as up-regulated genes (Fig. 2 and Table 4B). The nucleotide sequence of $6 / 2-3,6 / 2-4, \mathrm{M} / 2-1, \mathrm{M} / 2-2, \mathrm{M} / 6-1$ and 2/6-3 showed high similarity to etrA, fasciclin $I$, cyclin-dependent kinase 7 (cdk7), citrate synthase, corkscrew protein and proteasome $26 S$ subunit homologues, respectively. On the other hand, the 2/6-4 clone showed no similarity to known protein but was identified as silkworm genome BAAB01012899, the cDNA of which has not been identified yet. This showed multiple up-regulated patterns (Fig. 2B). The transcripts of etrA, corkscrew protein and proteasome subunit homologues were up-regulated at $2 \mathrm{~h}$ p.i., whereas that of fasciclin homologue was increased at $6 \mathrm{~h}$ p.i. Furthermore, the mRNA levels of both $c d k 7$ and citrate synthase homologues were transiently up-regulated at $2 \mathrm{~h}$ p.i. On the other hand, BAAB01012899 homologue showed an undetected 
Table 4. List of differentially expressed host genes

\begin{tabular}{|c|c|c|c|c|c|c|c|}
\hline & \multirow[b]{2}{*}{ Clone } & \multirow{2}{*}{$\begin{array}{c}\text { Database } \\
\text { clone name }\end{array}$} & \multirow[b]{2}{*}{ Clone identity } & \multirow[b]{2}{*}{ Accession no. ${ }^{b}$} & \multirow{2}{*}{$\begin{array}{l}\text { Functional } \\
\text { association }\end{array}$} & \multicolumn{2}{|c|}{ Expression pattern $^{\mathrm{c}}$} \\
\hline & & & & & & $\begin{array}{c}\text { cDNA } \\
\text { subtraction }\end{array}$ & $\begin{array}{c}\text { Northern } \\
\text { analysis }\end{array}$ \\
\hline \multirow{4}{*}{ A } & $6 / 2-1$ & NV120376.Seq & RNA polymerase II & P19387 & Transcription & $2<6$ & $M=2>6$ \\
\hline & $6 / 2-2$ & Br--1672X & $\begin{array}{l}\text { D. melanogaster } \\
\text { LD } 46360\end{array}$ & AY $119621^{\mathrm{e}}$ & Unknown & $2<6$ & $\mathrm{M}>2<6$ \\
\hline & $2 / 6-1$ & brP-1791 & Ferritin lower subunit & P07797 & Iron storage & $2>6$ & $M=2>6$ \\
\hline & $2 / 6-2$ & NRPG0148 & - & - & - & $2>6$ & $M=2>6$ \\
\hline \multirow{7}{*}{ B } & $6 / 2-3$ & wdS30747 & EtrA & A49910 & cAMP receptor & $2<6$ & $\mathrm{M}<2<6$ \\
\hline & $6 / 2-4$ & NV120322 & Fasciclin I precursor & P10675 & Cell adhesion & $2<6$ & $M=2<6$ \\
\hline & $\mathrm{M} / 2-1$ & ceN-5770 & Cdk7 & P50613 & $\begin{array}{l}\text { Transcription, } \\
\text { Cell cycle }\end{array}$ & $\mathrm{M}>2$ & $M<2>6$ \\
\hline & $\mathrm{M} / 2-2$ & N---0357 & Citrate synthase & O75390 & Energy metabolism & $\mathrm{M}>2$ & $M<2>6$ \\
\hline & M/6-1 & - & Corkscrew protein & $\mathrm{U} 22356^{\mathrm{e}}$ & $\begin{array}{l}\text { Tyrosine protein } \\
\text { phosphatase }\end{array}$ & $M>6$ & $M<2=6$ \\
\hline & $2 / 6-3$ & - & Proteasome 26S subunit & $\mathrm{AB} 003102^{\mathrm{e}}$ & Proteasome & $2>6$ & $M<2=6$ \\
\hline & $2 / 6-4$ & BAAB01012899 & - & - & - & $2>6$ & $\mathrm{M}<2>6$ \\
\hline \multirow{2}{*}{$\mathrm{C}$} & $2 / 6-5$ & ovS301G01f & - & - & - & $2>6$ & $M=2=6$ \\
\hline & $\mathrm{M} / 2-3$ & BAAB01021933 & - & - & - & $M>2$ & $M=2=6$ \\
\hline
\end{tabular}

Host genes were grouped by down- (A), up- (B) and non-regulated (C).

${ }^{a}$ SilkBase.

${ }^{\mathrm{b}}$ Accession numbers of PIR and SWISS-PROT.

${ }^{\mathrm{c}}>\mathrm{A}$, greater than $\mathrm{A} ;<\mathrm{A}$, less than $\mathrm{A} ;=\mathrm{A}$, equal to $\mathrm{A}$.

${ }^{\mathrm{d}}$ KAIKOBLAST.

${ }^{\mathrm{e}}$ Accession numbers of GenBank/EMBL/DDBJ.

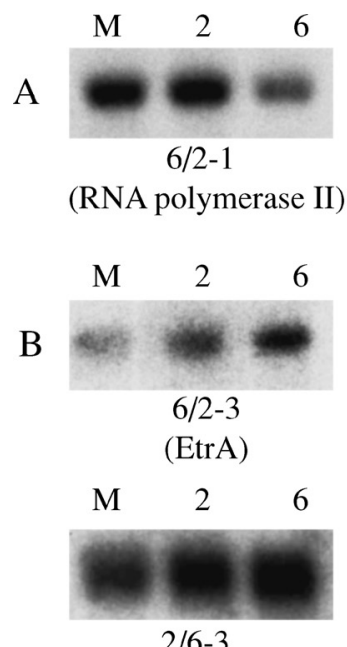

(Proteasome 26S subunit)

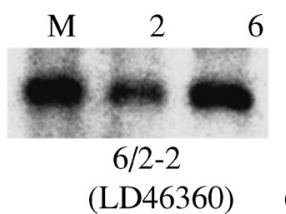

(LD46360)

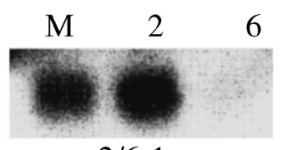

$2 / 6-1$

(Ferritin lower subunit)

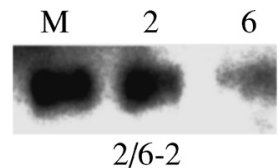

$2 / 6-2$

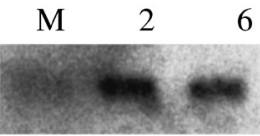

$\mathrm{M} / 2-1$

(Cdk7)

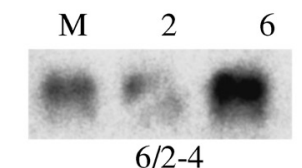

(Fasciclin I)

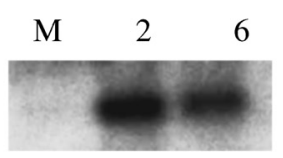

2/6-4

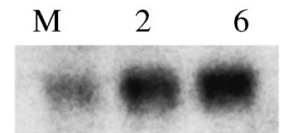

M/6-1

(Corkscrew protein)

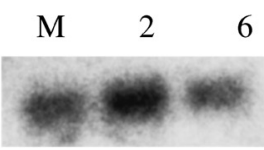

M/2-2

(Citrate synthase)
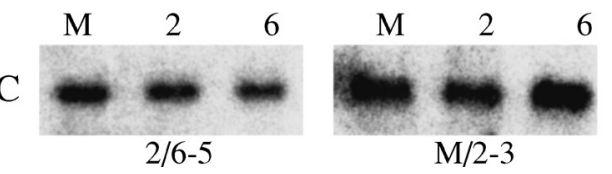

D

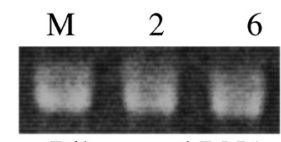

Ribosomal RNA

Fig. 2. Northern blot analysis of cDNA-subtracted BmN clones. Total RNA was extracted from BmN cells at mock, 2 and $6 \mathrm{~h}$ p.i. Clones were grouped by down- (A), up- (B) and non-regulated (C). Ribosomal RNA was used as an internal control (D). 
level of transcript at mock infection, and was then up-regulated from $2 \mathrm{~h}$ p.i.

It is known that Fasciclin, Cdk or Corkscrew has a function for general events in host cells. The protein encoded by fasciclin is an extracellular protein required for cell-to-cell adhesion (McAllister et al., 1992). Cdk is a component of RNA polymerase II transcriptional machinery (Serizawa et al., 1995; Shiekhattar et al., 1995) and also plays key roles in cell-cycle progression (Shuttleworth, 1995). On the other hand, Corkscrew is known as a protein tyrosine phosphatase that operates positively downstream of Drosophila receptor tyrosine kinase such as epidermal growth factor and the fibroblast growth factor receptor (Perkins et al., 1996); therefore, the up-regulation of these genes suggests that general events such as cell adhesion, cell cycle or cell/organism growth in host cells may be under the control of BmNPV.

Citrate synthase and the proteasome $26 \mathrm{~S}$ subunit are deeply involved in host energy metabolism. Citrate synthase is the initial enzyme of the tricarboxylic acid (TCA) cycle, which plays a central role in aerobic energy production and metabolite interconversions in mitochondria (Holloszy et al., 1970). In addition, this proteasome-ubiquitin pathway constitutes the major system for nuclear and extralysosomal cytosolic protein degradation depending on ATP (Golab et al., 2004). For virus infection, proteasome plays key roles for both the budding of retroviruses (Ott et al., 2003) and efficient lytic infection of herpesviruses (Everett, 1999). In addition, it has been suggested that ubiquitination plays important roles in baculovirus infection since baculoviruses encode ubiquitin ligases (Imai et al., 2003; Green et al., 2004). Therefore, the up-regulation of two homologues involved in the TCA cycle and proteasome suggest that these genes may function in the supply and demand of ATP, and that host energy metabolism is also under the control of BmNPV during infection.

\section{Non-regulated genes}

Although both 2/6-5 and M/2-3 were obtained as down-regulated clones from subtraction screening, these clones were confirmed as non-regulated clones in the early phase by Northern analysis (Table 4C and Fig. 2C). The nucleotide sequences of these clones showed no homology to known protein; however, 2/6-5 and M/2-3 were identified as
ovS301G01f clone from EST in SilkBase and BAAB01021933 in silkworm genome, respectively (Table 4C).

\section{Relative ADP/ATP ratio in BmN cells infected with BmNPV}

Our results showed that the expression of genes encoding the proteasome subunit homologue or citrate synthase homologue is up-regulated by BmNPV infection (Table 4B and Fig. 2B); therefore, the up-regulation of these homologue expressions suggests that the virus may require a higher level of gene expression involved in energy metabolism. To address the response of host energy metabolism to baculovirus infection, we measured ADP/ATP ratios. Bradbury et al. (2000) have shown that the ADP/ATP ratio indicates cell viability based on energy metabolism. A higher level of ATP and decrease in ADP result in a lower level of the ADP/ATP ratio that indicates cell proliferation, and a higher level of ADP/ATP ratio due to a lower level of ATP and increase in ADP indicates that cells are undergoing cell death such as apoptosis or necrosis (Bradbury et al., 2000). The ratios measured in mock-infected $\mathrm{BmN}$ cells were less than 0.2 between $0 \mathrm{~h}$ p.i. and $72 \mathrm{~h}$ p.i. (Fig. 3). On the other hand, the ratios in BmNPV-infected cells showed an increased pattern from the early to very

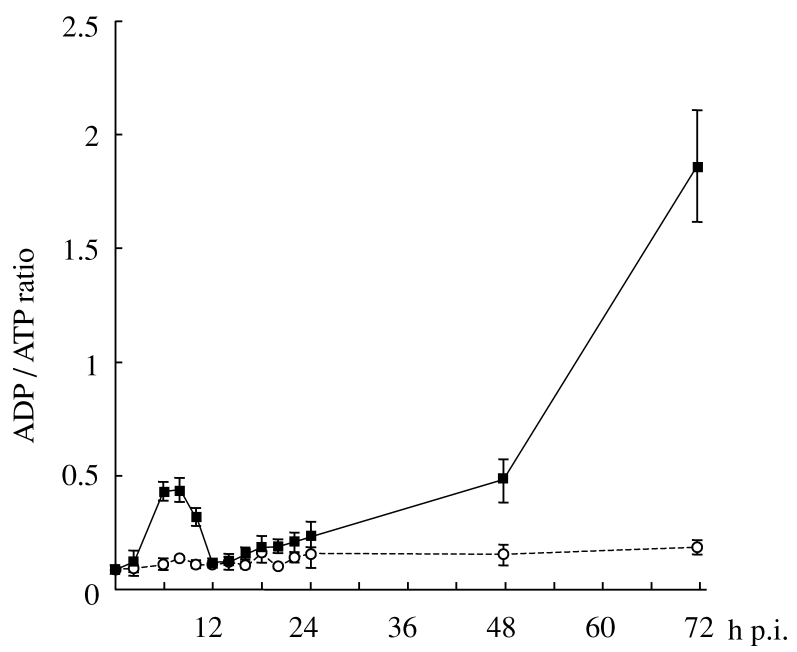

Fig. 3. Comparison of the ADP/ATP ratio in mock- (broken line with circles) or virus- (solid line with squares) infected $\mathrm{BmN}$ cells. BmN cells $\left(1 \times 10^{4}\right.$ cells $)$ were infected with $\mathrm{BmNPV}$ at an MOI of 10 . At indicated times, BmN cells were harvested and measured for ADP/ATP ratio. The results represented are the average of three independent experiments and standard errors are indicated. 
late phase although significant decrease was observed between $12 \mathrm{~h}$ p.i. and $24 \mathrm{~h}$ p.i. The ratios increased to 0.43 in the early phase (6-8 h p.i.) and to 1.86 in the very late phase $(72 \mathrm{~h}$ p.i.). The $\mathrm{ADP} / \mathrm{ATP}$ ratio at $72 \mathrm{~h}$ p.i. was 10 -fold larger than that of mock infection. It has been reported that the $\mathrm{ADP} / \mathrm{ATP}$ ratio at cell proliferation is less than 0.11 compared with ratios 10 - and 150-fold larger at apoptosis and necrosis in human leukaemic cells (Bradbury et al., 2000). Therefore, the ADP/ATP ratio at $72 \mathrm{~h}$ p.i. was regarded as close to apoptosis in leukaemic cells. Interestingly, the ADP/ATP ratios in NPV-infected BmN cells showed an increased pattern between $6 \mathrm{~h}$ p.i. and $10 \mathrm{~h}$ p.i., while a transiently decreased pattern between $12 \mathrm{~h}$ p.i. and $24 \mathrm{~h}$ p.i. (Fig. 3). In baculoviruses, it has been reported that several anti-apoptotic genes such as p35 and iap prevent premature cell death (Clem and Miller, 1993; Kamita et al., 1993; Birnbaum et al., 1994). It is contradictory that host cells appear to undergo apoptosis following NPV infection although anti-apoptotic genes of baculoviruses prevent host cell death. Therefore, the change of ADP/ATP ratios rather suggests the alteration of host energy metabolism by BmNPV infection. Furthermore, the increase of the ADP/ATP ratio in the very late phase of infection might indicate consumption of ATP value. As described above, the expression of the citrate synthase homologue was transiently up-regulated in the early phase (Fig. 2B). It has also been reported that genes that are active within mitochondria do not follow the host mRNA shutoff pattern (Ooi and Miller, 1988; Okano et al., 2001; Nobiron et al., 2003). These results suggest that the improvement of host energy metabolism is caused by the function of these gene transcripts, and may achieve the abrupt consumption of ATP for virus multiplication in BmNPV-infected insect cells. In conclusion, our cDNA subtraction approach suggests that BmNPV infection regulates intracellular events in host cells at the mRNA level.

\section{ACKNOWLEDGEMENTS}

We are grateful to M. Kurihara for technical assistance. This research was supported by grants from the COE (Center of Excellence), Bioarchitect program of the Science and Technology Agency of Japan (W.K.), Junior Research Associate program of RIKEN and Research Fellowships of the Japan Society for the Promotion of Science for Young Scientists (M.I.).

\section{REFERENCES}

Belyavskyi, M., S. C. Braunagel and M. D. Summers (1998) The structural protein ODV-EC27 of Autographa californica nucleopolyhedrovirus is a multifunctional viral cyclin. Proc. Natl. Acad. Sci. USA 95: 11205-11210.

Birnbaum, M. J., R. J. Clem and L. K. Miller (1994) An apoptosis-inhibiting gene from a nuclear polyhedrosis virus encoding a polypeptide with $\mathrm{Cys} / \mathrm{His}$ sequence motifs. J. Virol. 68: 2521-2528.

Bradbury, D. A., T. D. Simmons, K. J. Slater and S. P. M. Crouch (2000) Measurement of the ADP : ATP ratio in human leukaemic cell lines can be used as an indicator of cell viability, necrosis and apoptosis. J. Immunol. Methods 240: 79-92.

Braunagel, S. C., R. Parr, M. Belyavskyi and M. D. Summers (1998) Autographa californica nucleopolyhedrovirus infection results in $\mathrm{Sf} 9$ cell cycle arrest at G2/M phase. Virology 244: 195-211.

Carstens, E. B., S. T. Tija and W. Doerfler (1979) Infection of Spodoptera frugiperda cells with Autographa californica nuclear polyhedrosis virus. I. Synthesis of intracellular proteins after virus infection. Virology 99: 386-396.

Choudary, P. V., S. G. Kamita and S. Maeda (1995) Expression of foreign genes in Bombyx mori larvae using baculovirus vectors. In Methods in Molecular Biology-Baculovirus Expression Protocols (C. D. Richardson ed.). Humama Press, Totowa, pp. 243-264.

Clem, R. J. and L. K. Miller (1993) Apoptosis reduces both the in vitro replication and the in vivo infectivity of a baculovirus. J. Virol. 67: 3730-3738.

Everett, R. D. (1999) A surprising role for the proteasome in the regulation of herpesvirus infection. Trends Biochem. Sci. 24: 293-295.

Golab, J., T. M. Bauer, V. Daniel and C. Naujokat (2004) Role of the ubiquitin-proteasome pathway in the diagnosis of human disease. Clin. Chim. Acta 340: 27-40.

Green, M. C., K. P. Monser and R. J. Clem (2004) Ubiquitin protein ligase activity of the anti-apoptotic baculovirus protein Op-IAP3. Virus Res. 105: 89-96.

Grula, M. A., P. L. Buller and R. F. Weaver (1981) $\alpha$-Amanitin-resistant viral RNA synthesis in nuclei isolated from nuclear polyhedrosis virus-infected Heliothis zea larvae and Spodoptera frugiperda cells. J. Virol. 38: 916-921.

Holloszy, J., L. B. Oscai, I. J. Don and P. A. Mole (1970) Mitochondrial citric acid cycle and related enzymes: adaptive response to exercise. Biochem. Biophys. Res. Commun. 40: 1368-1373.

Hoopes, R. J. and G. F. Rohrmann (1991) In vitro transcription of baculovirus immediate early genes: Accurate mRNA initiation by nuclear extract from both insect and human cells. Proc. Natl. Acad. Sci. USA 88: 45134517.

Imai, N., N. Matsuda, K. Tanaka, A. Nakano, S. Matsumoto and W. Kang (2003) Ubiquitin ligase activities of Bombyx mori nucleopolyhedrovirus RING finger proteins. $J$. Virol. 77: 923-930.

Iwanaga, M., W. Kang, M. Kobayashi and S. Maeda (2000) Baculovirus infection blocks the progression of fat body 
degradation during metamorphosis in Bombyx mori. Arch. Virol. 145: 1763-1771.

Iwanaga, M., M. Kurihara, M. Kobayashi and W. Kang (2002) Characterization of Bombyx mori nucleopolyhedrovirus orf 68 gene that encodes a novel structural protein of budded virus. Virology 297: 39-47.

Iwanaga, M., K. Takaya, S. Katsuma, M. Ote, S. Tanaka, S. G. Kamita, W. Kang, T. Shimada and M. Kobayashi (2004) Expression profiling of baculovirus genes in permissive and nonpermissive cell lines. Biochem. Biophys. Res. Cummun. 323: 599-614.

Kamita, S. G., K. Majima and S. Maeda (1993) Identification and characterization of the $p 35$ gene of Bombyx mori nuclear polyhedrosis virus that prevents virus-induced apoptosis. J. Virol. 67: 455-463.

Lanier, L. M. and L. E. Volkman (1998) Actin binding and nucleation by Autographa californica M nucleopolyhedrovirus. Virology 243: 167-177.

Maeda, S. (1989) Gene transfer vectors of a baculovirus, Bombyx mori, and their use for expression of foreign genes in insect cells. In Invertebrate Cell System Application (J. Mitsuhashi ed.). CRC Press, Inc., Boca Raton, pp. $167-181$

Maeda, S. (1995) Further development of recombinant baculovirus insecticides. Curr. Opin. Biotechnol. 6: 313319.

Maeda, S., T. Kawai, M. Obinata, H. Fujiwara, T. Horiuchi, Y. Saeki, Y. Sato and M. Furusawa (1985) Production of human alpha-interferon in silkworm using a baculovirus vector. Nature 315: 592-594.

McAllister, L., C. S. Goodman and K. Zinn (1992) Dynamic expression of the cell adhesion molecule fasciclin I during embryonic development in Drosophila. Development 115: 267-276.

Mita, K., M. Morimyo, K. Okano, Y. Koike, J. Nohata, H. Kawasaki, O. K. Kadono, K. Yamamoto, G. M. Suzuki, T. Shimada, M. R. Goldsmith and S. Maeda (2003) The construction of an EST database for Bombyx mori and its application. Proc. Natl. Acad. Sci. USA 100: 1412114126.

Nobiron, I., D. R. O'Reilly and J. A. Olszewski (2003) Autographa californica nucleopolyhedrovirus infection of Spodoptera frugiperda cells: a global analysis of host gene regulation during infection, using a differential display approach. J. Gen. Virol. 84: 3029-3039.

Okano, K., T. Shimada, K. Mita and S. Maeda (2001) Comparative expressed-sequence-tag analysis of differential gene expression profiles in BmNPV-infected $\mathrm{BmN}$ cells. Virology 282: 348-356.

Ooi, B. G. and L. K. Miller (1988) Regulation of host RNA levels during baculovirus infection. Virology 166: 515-
523.

O'Reilly, D. R., L. K. Miller and V. A. Luckow (1992) Choice of virus and host species. In Baculovirus Expression Vectors: A Laboratory Manual (W. H. Freeman ed.). Oxford Univ. Press, New York, pp. 33-37.

Ott, D. E., L. V. Coren, R. C. Sowder, J. Adams and U. Schubert (2003) Retroviruses have differing requirements for proteasome function in the budding process. $J$. Virol. 77: 3384-3393.

Perkins, L. A., M. R. Johnson, M. B. Melnick and N. Perrimon (1996) The nonreceptor protein tyrosine phosphatase corkscrew functions in multiple receptor tyrosine kinase pathway in Drosophila. Dev. Biol. 180: 63-81.

Prikhod'ko, E. A. and L. K. Miller (1998) Role of baculovirus IE2 and its RING finger in cell cycle arrest. $J$. Virol. 72: 684-692.

Roncarati, R. and D. Knebel-Morsdorf (1997) Identification of the early actin-rearrangement-inducing factor gene, arif-1, from Autographa californica multicapsid nuclear polyhedrosis virus. J. Virol. 71: 7933-7941.

Sahara, S., M. Aoto, Y. Eguchi, N. Imamoto, Y. Yoneda and Y. Tsujimoto (1999) Acinus is a caspase-3-activated protein required for apoptotic chromatin condensation. $\mathrm{Na}$ ture 401: 168-173.

Serizawa, H., T. P. Makela, J. W. Conaway, R. C. Conaway, R. A. Weinberg, R. A. Young (1995) Association of Cdkactivating kinase subunits with transcription factor TFIIH. Nature 374: 280-282.

Shackel, N. A., P. H. McGuinness, C. A. Abbott, M. D. Gorrell and G. W. McCaughan (2003) Novel differential gene expression in human cirrhosis detected by suppression subtractive hybridization. Hepatology 38: 577-587.

Shiekhattar, R., F. Mermelstein, R. P. Fisher, R. Drapkin, B. Dynlacht, H. C. Wessling, D. O. Morgan and D. Reinberg (1995) Cdk-activating kinase complex is a component of human transcription factor. Nature 374: 283-287.

Shuttleworth, J. (1995) The regulation and functions of $c d k 7$. Prog. Cell Cycle Res. 1: 229-240.

Su, Z. Z., Y. Shi and P. B. Fisher (1997) Subtraction hybridization identifies a transformation progression-associated gene $P E G-3$ with sequence homology to a growth arrest and DNA damage-inducible gene. Proc. Natl. Acad. Sci. USA 94: 9125-9130.

Sugimori, H., T. Nagamine and M. Kobayashi (1991) Protein synthesis in BmN cells infected with Bombyx mori nuclear polyhedrosis virus. J. Invertbr. Pathol. 58: 257268.

Xu, J. P., K. P. Chen, Q. Yao, M. H. Liu, G. T. Gao and Y. Zhao (2005) Identification and characterization of an NPV infection-related gene Bmsop 2 in Bombyx mori L. $J$. Appl. Entomol. 129: 425-431. 